\title{
On the Viability of a Multilateral Trade Agreement: A Political-Economy Approach'
}

\author{
Danilo R. Trupkin \\ Universidad de Montevideo • Montevideo, Uruguay
}

\begin{abstract}
The big picture issue this paper intends to address is on the incentive aspects of a multilateral trade liberalization. The paper builds on a framework originally introduced in Grossman and Helpman's The Politics of Free-Trade Agreements (1995). The aim of that work was to explain the viability of free trade agreements (FTAs) between two countries in a political-economy framework. A simple extension to a three-country setting allows us to analyze whether FTAs are "building blocs" or "stumbling blocs." An illustration with specific functional forms serves to find conditions under which FTAs are, somehow, partial building blocs, i.e., a bilateral liberalization can be feasible when multilateral liberalization is not.
\end{abstract}

\section{Introduction}

A large number of preferential trade agreements (PTA) do exist nowadays all around the world. According to the World Trade Organization (WTO), more than 200 are in effect today. Almost all major countries are members of at least one PTA, and, most importantly, the majority of these agreements were originated during the last decade.

Bhagwati (1995) has called this scenario a "spaghetti bowl" of tariffs in which countries impose different tariff rates on the same good depending on its origin. In an earlier paper, Bhagwati (1991) addresses this issue by analyzing whether freetrade agreements (FTAs) are building blocs or stumbling blocs to the achievement of a broad multilateral agreement.

Since Viner's (1950) analysis on the welfare effects of customs unions, research interests in this topic have considerably caught the attention of international trade theorists. Viner pioneered the static analysis of trade agreements providing the message that these arrangements could harm both a member country and world welfare, i.e., they can be "trade diverting.".

There have been concerns recently in regards to the viability of a successful multilateral trade liberalization in a world that is largely populated by potentially harmful FTAs. ${ }^{3}$ In this line, Krishna (1998) asks the political-economy question of whether FTAs have incentives to keep expanding with more members toward a multilateral liberalization, or, instead, they wish to keep new members out. On the other 
hand, Aghion et al. (2007) address the question of regionalism versus multilateralism by investigating whether multilateral bargaining or sequential bargaining are more likely to lead to global free trade.

The "stumbling-bloc" view of FTAs has been supported, among others, by Bhagwati $(1991,1993)$ who finds that, even though FTAs may generate static welfare gains, they finally reduce the incentives to seek posterior trade liberalization. Yet, others such as Summers (1991) argue that deeper integration within a subset of countries may raise the chances for successful multilateral negotiations. An interesting recent work by Saggi and Yildiz (2006) finds both stumbling-bloc and building-bloc effects, and illustrates cases in which trade agreements are "partial building blocs," i.e., FTAs can improve welfare when multilateral liberalization is not attainable.

The focus of this paper is both on the incentive aspects that explain the formation of trade blocs and on the viability of a multilateral agreement. The approach followed belongs to the political-economy theory literature on international trade. In particular, this paper builds on a framework, first introduced in Grossman and Helpman (1995). They analyze the viability of an FTA between two countries approaching the political-economy problem by emphasizing the interaction between lobbies and an incumbent government. That paper considers both the case when the FTA must cover all bilateral trade and the case when some politically sensitive industries can be excluded from the agreement.

In Grossman-Helpman (1995), international relations involve two distinct stages of strategic interaction. In the initial stage, political competition among special interests in each country - the lobbies — determines the government's trade policy preferences. The second stage involves the bargaining process between the governments, which ultimately shapes the equilibrium agreement. The initial stage in which lobbies in a single country compete for the government's external policy makes use of the analytical framework previously introduced in Grossman and Helpman (1994). In that earlier model, lobbies offer policy-contingent campaign contributions to politicians, who make decisions on the basis of their own objectives. Thus, a country's policy stance reflects, on the one hand, the relative force of its special interests and, on the other hand, the government's concern for the welfare of the average voter.

According to this approach, an agreement may emerge when it creates profit gains for exporting sectors in excess of the losses incurred by import-competing sectors and any welfare losses to the average voter. Naturally, an FTA requires that the two governments give consent to the agreement. In this setting, the agreement is most likely to emerge when there is relatively balanced trade between both countries, and when the agreement provides mostly enhanced protection - exporting 
sectors receiving high domestic prices in the partner country — rather than reduced protection - import-competing sectors receiving a lower domestic price product of the FTA.

It turns out that reduced protection may involve some trade creation whereas enhanced protection generates only trade diversion. Thus, the Grossman-Helpman analysis of FTAs establishes that the features raising the viability of an agreement also raises the likelihood that this agreement finally reduces social welfare. They also show that a set of industry exclusions might make an otherwise infeasible FTA politically viable. They study the determinants of the size of this set and identify the sensitive industries. ${ }^{4}$

This paper develops a three-country political-economy representation model in order to find conditions for the viability of a multilateral agreement. First, the model takes the two-country FTA game as the starting point to evaluate the prospects of ulterior multi-lateral negotiations. Second, the model studies the prospects of multilateral liberalization, departing from the status quo. A three-country set up allows us to move the focus of the analysis toward the question of whether trade blocs are building blocs or stumbling blocs. An illustration with specific functional forms serves to find conditions under which FTAs are, in some way, partial building blocs, i.e., a bilateral trade agreement can be feasible when multilateral liberalization is not.

The paper proceeds as follows. Section 2 describes the Grossman-Helpman's model of FTAs in order to introduce the framework used throughout the paper. Section 3 extends this model to a three-country setting in which the viability of successful multilateral negotiations is analyzed. This section extends formally the general analysis introduced in the preceding section. Section 4 assumes particular functional forms so as to illustrate how that model works in a world with the possibility of multilateral liberalization. Section 5 concludes.

\section{The Grossman-Helpman Model of FTAs}

\section{A Review of the Analytical Framework}

Consider two small countries and the rest of the world. Each country charges non-discriminatory most-favored-nation (MFN) tariffs, following WTO rules. There is a numeraire good 0 that is untaxed in each country, and $n$ other goods. Initially, some of these goods are imported by one or both of these countries while others may be exported. Neither export subsidies are allowed in the model in recognition of WTO rules nor are export taxes. International prices are normalized to 1, thus domestic export prices are simply 1. As for the import goods, these may be subject to 
import tariffs. Let $\tau_{j}^{i}$ represent 1 plus the initial tariff rate on good $i$ in country $j$, for $j=A, B$. By normalizing international prices to 1 , then these are the domestic prices of import goods in country $j$.

Assume that, after the conclusion of an FTA, the initial external tariff levels continue to apply to imports from nonmember countries. This is made according to WTO rules which establish that these tariffs must be no higher than those imposed before the agreement. ${ }^{5}$ Article XXIV of the General Agreement on Tariffs and Trade (GATT) permits certain exceptions to the principle of MFN, provided that the agreement covers "substantially all trade". Although the interpretation of this article could be somewhat misleading, the first part of this model analyzes the viability of an FTA requiring that all goods be freely traded between the members. The second part will consider exclusions of sectors that might be sensitive to the agreement.

Each country has a (voting) population of 1 . Individuals in each country have identical preferences

$$
u(c)=c_{0}+\sum_{i=1}^{n} u_{i}\left(c_{i}\right)
$$

where $c_{i}$ denotes consumption of good $i$, and $u_{i}($.$) is an increasing and concave$ function. Consistent with these preferences, there are $n$ per capita demand for the $n$ goods, $D_{i}\left(q_{i}\right)$, and one per capita demand for good $0, y-\sum_{i=1}^{n} q_{i} D_{i}\left(q_{i}\right)$, where $q_{i}$ is the domestic consumer price of good $i$ and $y$ is the individual's spending.

The production of a unit of good 0 requires only one unit of labor whereas each of the $n$ goods is produced under constant returns to scale with labor and a sector-specific factor. Since the domestic price of good 0 is normalized to 1 , the competitive wage must equal 1 provided there is some production of this good initially. Denote with $\Pi_{i}\left(p_{i}\right)$ the profits earned by the specific factor in sector $i$, where $p_{i}$ is its domestic producer price. Denote by $X_{i}$ the aggregate supply of good $i$, which is given by $X_{i}\left(p_{i}\right)=\Pi_{i}^{\prime}\left(p_{i}\right)>0$ for each $i$.

Assume that the ownership of specific factors is highly concentrated and consider the extreme case where these factor owners are a negligible fraction of the population. Also, assume that in each sector $i$ these factor owners form a special-interest group (a lobby) which takes political action so as to maximize their joint welfare.

The incumbent government has as its only function the decision on trade policy, which, in this case, reduces to whether accept or reject the FTA. Politicians in the government receive contributions from the lobbyists who seek to influence their decision. The government does not only value these contributions, but also cares about aggregate welfare. 
Assume that the government's objective has a simple linear form

$$
G=\sum_{i=l}^{n} C_{i}+a W
$$

where $C_{i}$ is the contribution of lobby $i, W$ is aggregate welfare, and $a$ is a non-negative parameter reflecting the government's welfare maximizing behavior relative to contributions. In turn, the individual's surplus from consuming good $i$ is

$$
S_{i}\left(q_{i}\right) \equiv u_{i}\left[D_{i}\left(q_{i}\right)\right]-q_{i} D_{i}\left(q_{i}\right)
$$

The consumer also receives a lump-sum transfer from the government determined by the equally rebated, total tariff revenues. Finally, aggregate welfare is given by

$$
W=L+\sum_{i=1}^{n} \Pi_{i}\left(p_{i}\right)+\sum_{i=1}^{n}\left(\tau_{i}-1\right) M i+\sum_{i=1}^{n} S_{i}\left(q_{i}\right)
$$

where the first term, $L$, is the aggregate labor supply, and $M_{i}$ are imports in sector $i$. Remember that if the wage is 1 , then $W$ will be the sum of labor income, profits, tariff revenues, and total consumer surplus.

Since factor owners capture only a negligible fraction of the consumer surplus and receive only a negligible fraction from tariff revenues, the objective of these owners may be approximated by $\Pi_{i}(p)-C_{p}$ i.e., profits net of contributions.

The domestic political game comprises two stages. In the first stage, lobbies make their move, offering financial support - the contributions - to the incumbent government. These contributions are directly linked to the government's policy, which is simply the acceptability or rejection of the trade agreement. In the second stage, the government has two choices: whether to pursue the FTA or not. In the end, a factor-owner policy-contingent contribution schedule will only encompass two numbers: $C_{i N}$, representing the contributions in favor of the status-quo, and $C_{i F}$, representing the contributions in favor of the FTA.

Finally, assume that each lobby offers in contributions no more than what it stands to gain if the government were to follow its bidding.

\section{Effects of an FTA}

Consider the effects of an FTA on the interests of the different economic agents. To begin with, focus on a single industry $i$ where, without loss of generality, assume that $\tau_{i}^{A}>\tau_{i}^{B} \geq 1$. That is, the domestic price in country $\mathrm{A}$ is greater than that 
in country B, which in fact is no lower than that prevailing in the rest of the world. Figure 1 depicts the demand for imports by country $A$ and three possible locations of country B's supply curve - locations that depend on the endowments of the specific factor used in this industry.

Figure 1

The Free Trade Agreement

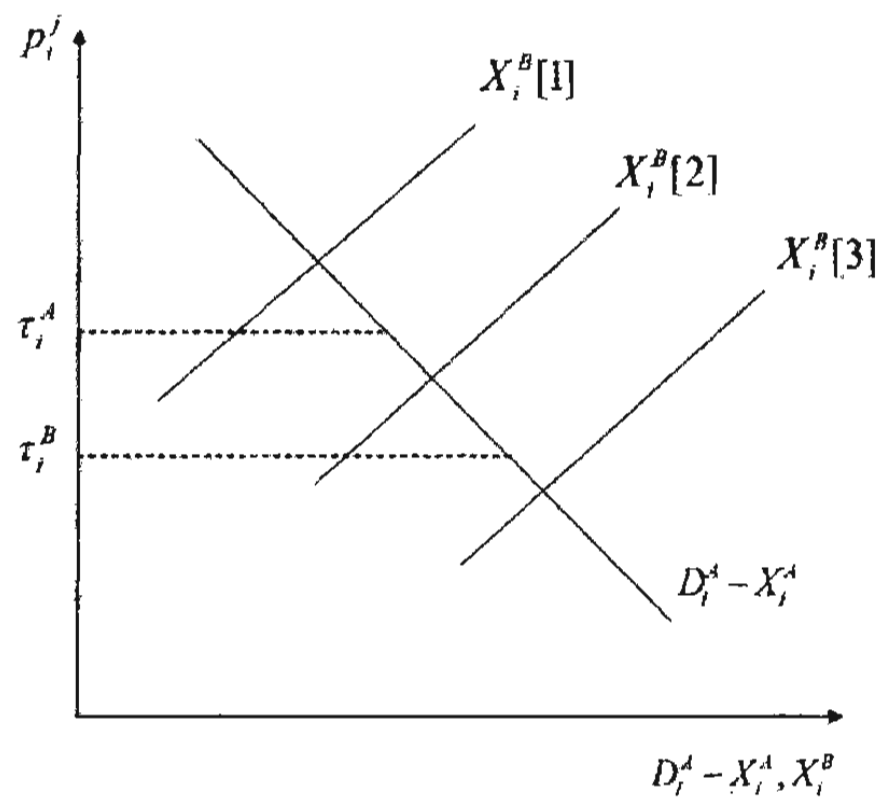

Consider two effects of an FTA on country members. On the one hand, if country B's supply of good $i$ is relatively small to suffice country A's import demand, as the case of $X_{i}^{B}$ [1] then the equilibrium producer price received by industries in the lower-tariff country will rise toward $\tau_{i}^{A}$. This is the case of enhanced protection. In contrast, the endowment of specific factor in country B may be so large that it suffices to satisfy A's import demand at the lower price $\tau_{i}^{B} i$ - situation depicted by supply curve $X_{i}^{B}[3]$. In this case, A's import-competing industries see their price falling as well as their profits. This is the case of reduced protection. There is also an intermediate case whenever the supply in country B lies between the higher and the lower price, with the results being a combination of the two previous effects.

In order to illustrate the two extreme cases, consider now an industry that experiences enhanced protection. Producers in B benefit from their preferential access to A's market whereas producers in A are unaffected, given that their domestic price does not change. Regarding the welfare in A, the only effect is the decrease in tariff revenues, which is an adverse effect product of the diverted trade from the more efficient rest of the world to the partner B. The total welfare change in A is 
$\Delta W_{i}^{A}=-\left(\tau_{i}^{A}-1\right) X_{i}^{B}\left(\tau_{i}^{A}\right)$

In country B, aggregate welfare necessarily rises because of two components: first, profits of the export sector increase given the higher price received in market $\mathrm{A}$; second, the country substitutes domestic supply with international supply, thus gaining from an increase in tariff revenues. The total welfare change in $B$ is

$$
\Delta W_{i}^{B}=\Delta \Pi_{i}^{B}+\left(\tau_{i}^{B}-1\right) X_{i}^{B}\left(\tau_{i}^{B}\right)
$$

It is straightforward to show that the welfare loss in A exceeds the welfare gain in $\mathrm{B}$, which reveals the global efficiency cost of the trade diversion effect.

As for the reduced protection case, one can see that exporters in B gain nothing from the agreement, while producers in $A$ bear the increased import competition. Since all imports in A come from B now, tariff revenues from this sector fall to zero. However, average voters in this country gain as consumers, since the domestic price in A decreases toward $\tau_{i}^{B}$. The change of aggregate welfare in $\mathrm{A}$ is

$$
\Delta W_{i}^{A}=\Delta \Pi_{i}^{A}-\left(\tau_{i}^{A}-1\right) M_{i}^{A}\left(\tau_{i}^{A}\right)+S_{i}^{A}\left(\tau_{i}^{B}\right)-S_{i}^{A}\left(\tau_{i}^{A}\right),
$$

which may be positive or nonpositive.

Country $B$ receives only the extra tariff revenue generated by the partial substitution of domestic supply with foreign supply. Welfare change in B is

$$
\Delta W_{i}^{B}=\left(\tau_{i}^{B}-1\right) M_{i}^{A}\left(\tau_{i}^{B}\right)
$$

It is easy to see that welfare gains for the FTA members are assured in the reduced protection case. This arises from the trade creation effect of trading blocs in this set up.

As regards to the intermediate case, it simply combines features of the first two scenarios, and the result is ambiguous in terms of the joint welfare of the bloc.

\section{Equilibrium FTAs Without Exceptions}

First, 1 look for the conditions under which an FTA will be unilaterally supported in each country. Then, I study the conditions under which the negotiations between countries lead to an equilibrium agreement. 
Suppose that no exclusions (or side-payments) are allowed, so that either all industries are included in the FTA or the status quo prevails. Under this setting, a necessary and sufficient condition for an FTA equilibrium to occur is that both countries unilaterally favor it. Thus, consider first a game between lobbies and the government in each country determining the conditions for a unilateral stance that either favors the agreement (outcomes will be denoted with subscript $F$ ), or favors the status quo (outcomes will be denoted with subscript $N$ ).

At this point, I will apply a simplified version of Grossman-Helpman's mode] developed by Goldberg and Maggi (1999). In this version, a unilateral stance equilibrium results simply from the maximization problem of the joint surplus of the government and domestic lobbies - which I loosely call the "political welfare". Therefore, the government unilaterally will favor an FTA if and only if,

$$
\sum_{i} \Pi_{i F}+a W_{F} \geq \sum_{i} \Pi_{i N}+a W_{N}
$$

Thus, the government will simply favor the agreement if the political welfare under the FTA weakly exceeds the political welfare under the status quo. It is certainly possible that inequality (9) fails to hold in either of the two countries, making the FTA infeasible. It is shown that the viability of an FTA that does not allow for industry exclusions depends on how balanced is the trade between potential members of the agreement. In words of Gawande et al. (2005), " an FTA among countries is most likely when trade between them is sufficiently 'balanced'." In showing this result, Grossman and Helpman consider a special case with specific functional forms and parameters. In fact, I will work on that example below in order to put some structure to the general specification of the three-country setting.

\section{Equilibrium FTAs With Exceptions}

Grossman and Helpman (1995) show how industry exclusions may make an otherwise infeasible FTA politically viable. At this stage, consider the game between lobbies and the government in which a unilateral stance for an FTA with exclusions is determined.

Denote as $\varepsilon(T)$ the set of politically optimal exclusions, where $T$ is assumed to be the maximum number of excluded industries. ${ }^{6}$ If there was no such limit $T$, then all industries having the joint welfare of lobby and government higher in the status quo than under the FTA would belong to that set. For future consideration, denote the change in joint welfare of sector $i$ as 


$$
g_{i}=\Delta \Pi_{i}+a \Delta W_{i}
$$

where $\Delta \Pi_{i}=\Pi_{i F^{\prime}}-\Pi_{i N}$ and $\Delta W_{i}=W_{i F^{-}}-W_{i N^{*}}$. Notice that if no restrictions were imposed, the set of exclusions would comprise all industries for which $g_{i}<0$.

Consider the case where there is indeed a constraint $T$ on the number of exclusions. Then, it is not hard to see that when this constraint binds, the $T$ excluded industries would be those with the most negative joint welfare change. Grossman and Helpman show that a unilateral stance for an FTA does exist if and only if

$$
\sum_{i \in \varepsilon}\left(\Pi_{i N}+a W_{i N}\right)+\sum_{i \notin \varepsilon}\left(\Pi_{i F}+a W_{i F}\right) \geq \sum_{i} \Pi_{i N}+a W_{i N}
$$

The central finding is that while (9) may fail to hold, inequality (11) can be satisfied. That is, whereas a unilateral stance favoring an FTA without exclusions may fail, a unilateral stance for an FTA in which the most sensitive industries can be excluded may favor the agreement. Following Gawande et al. (2005), one can rewrite (9) as $\sum g_{i} \geq 0$, and (11) as $\sum_{i \notin \varepsilon} g_{i} \geq 0$. Since the latter excludes the sectors with most negative joint welfare changes, it is clear that inequality (11) is easier to be satisfied.

In this stance, import-competing industries are the most politically sensitive sectors in the economy. Thus, they are the first candidates to push the government for being excluded from the agreement. In contrast, industries that can eventually export to the partner country at the expense of the rest of the world are the most favored by the agreement and they make contributions to the government in order to be included.

Consider now the next stance where both governments negotiate for the agreement. Assuming that unilateral stances in each country favored an agreement, at this stage both governments bring their lists of exclusions to the bargaining table in order to get a favorable FTA with their sensitive sectors excluded. In this sense, lobbies anticipate each possible outcome in making their bids.

Now, the question is which sectors will be granted exclusions in an equilibrium agreement. To solve this problem, Grossman and Helpman treat the negotiation process as a cooperative bargaining game and apply a simple Nash bargaining solution. Therefore, an equilibrium agreement will be designed so that it maximizes a weighted average of the surpluses of the two negotiating governments.

Since both governments have always the option to reject the agreement, their surpluses are calculated with respect to the status quo. Technically, the "threat point" in the Nash problem will be the joint welfare of government and domestic lobbies under the pre-FTA scenario. ${ }^{7}$ 
From the resulting equilibrium, it follows that exclusions are granted to industries for which the weighted difference between the political benefits in the exporting country and the political costs in the importing country is most negative. One can also identify the sector excluded through an ordering that depends only on aggregate conditions and on supply and demand characteristics. It turns out that the same factors that determine the politically optimal set of exclusions in each country at a unilateral stance also enter into the configuration of the set of exclusions in the negotiation between partners. The following section compares these results with the results one finds in a three-country model.

\section{The Multilateral Trade Agreement}

In the previous section, I described the Grossman and Helpman's (1995) model of FTAs, where the analysis is centered on two small countries and the rest of the world. Now, I consider a world of three countries denoted by $A, B$, and $C$, and study the viability of a multilateral trade agreement. The first subsection will assume that two of them are already members of an FTA. The second subsection will evaluate the prospects of a multilateral agreement, starting from the status quo. The next task is to compare which of both positions (either FTA or status quo) are closer to the possibility of global free trade. I could have alternatively considered a more general problem with endogenous formation of either an FTA between any two countries or a multilateral agreement. However, since my interest is to characterize the prospects of multilateral liberalization both before and after the formation of an FTA, it is beyond the scope of this study to endogenize the country's choice of a partner or group of partners. In particular, my final goal is to analyze the effects of preferential trade agreements formed in the Grossman-Helpman's context on the viability of a multilateral liberalization.

\section{Multilateral Liberalization with FTAs}

As in the preceding section, I begin here with the analysis of the viability of a trade agreement without exceptions. First, consider the game between lobbies and the government. Also as before, the maximization problem of the joint surplus of government and domestic lobbies brings about a unilateral stance equilibrium in each country. Assume, without loss of generality, that countries $A$ and $B$ are members of an FTA. Then, governments $A$ and $B$ will unilaterally favor a multilateral agreement (outcomes are denoted with subscript $M$ ) if and only if, 


$$
\sum_{i} \Pi_{i M}^{j}+a W_{M}^{j} \geq \sum_{i} \Pi_{i F}^{j}+a W_{F}^{j}, \text { for } j=A, B
$$

i.e., if the political welfare from multilateral liberalization is greater than that from the FTA in each country. Country $C$ will unilaterally favor a multilateral agreement if and only if,

$$
\sum_{i} \Pi_{i M}^{C}+a W_{M}^{C} \geq \sum_{i} \Pi_{i N}^{C}+a W_{N}^{C}
$$

i.e., country $\mathrm{C}$ will favor an agreement if and only if the political welfare under multilateral liberalization is greater than the one under status quo.

The analysis of the viability of a multilateral trade agreement with no exceptions turns out to be straightforward. Now, consider the viability of an equilibrium multilateral trade agreement with industry exclusions, by first introducing the game between lobbies and government at a unilateral stance.

I denote by $E(T)$ the set of politically optimal exclusions to the multilateral agreement. This set may differ with respect to the previous set of exclusions from the FTA -- the set $\varepsilon(T) .{ }^{8}$ Continue denoting the change in joint welfare by $g_{i}=\Delta \Pi_{i}$ $+a \Delta W_{i}$, where the changes are expressed with respect to the FTA in countries $A$ and $B$, and with respect to status quo in $C$.

It is straightforward to replicate inequality (11), which shows the conditions for a unilateral stance bilateral agreement with exclusions, for the multilateral case. Thus, the multilateral liberalization is favored in countries $A$ and $B$ if and only if

$$
\begin{aligned}
& \sum_{i \in \varepsilon}\left(\Pi_{i \tilde{N}}+a W_{i \hat{N}}^{j}\right)+\sum_{i \in \varepsilon}\left(\Pi_{i M}^{j}+a W_{i M}^{j}\right) \geq \sum_{i \in \varepsilon}\left(\Pi_{i N}^{j}+a W_{i N}^{j}\right)+ \\
& \sum_{i \varepsilon \varepsilon}\left(\Pi_{i F}^{j}+a W_{i F}^{j}\right)
\end{aligned}
$$

for $j=A, B$.

On the other side, country $C$ favors the agreement if and only if

$$
\sum_{i \in \varepsilon}\left(\Pi_{i N}^{C}+a W_{i N}^{c}\right)+\sum_{i \notin \varepsilon}\left(\Pi_{i M}^{C}\right) \geq \sum_{i}\left(\Pi_{i N}^{C}+a W_{i N}^{C}\right)
$$

The subscript " $\tilde{N}$ " in expression (14) is used to distinguish between the outcome of industries excluded from the multilateral agreement and that of industries excluded from the FTA - expressed with the subscript " $N$ ". Notice that a particular sector in either of countries $A$ or $B$ can contribute in two ways for an exception to the multilateral agreement. It can contribute to continue with the behavior as in status quo prevailing before the FTA was approved, as an industry already excluded 
from the FTA. Or, it can contribute to stay "inside" the FTA, which still is a possible scenario if the multilateral agreement is rejected. Once again, one can observe that, while inequality (13) for country $C$ may fail to hold, inequality (15) can hold if one allows for the most sensitive industries to be excluded. Notice that this may not be the case for countries $A$ and $B$, since inequality (14) introduces two sets of exclusions, one arising from the FTA and the other arising from the multilateral agreement.

Now consider the next stage where all the governments bargain for the multilateral agreement. As in Grossman and Helpman (1995), each government exposes its list of exclusions at the bargaining table. As in the previous section, I will analyze the negotiation process through the implementation of a Nash bargaining problem. It has been proved that the properties of a Nash bargaining solution with two players continue to apply in an $n$ - player bargaining game (see Krishna and Serrano, 1996). Then, the equilibrium agreement will be designed to maximize a weighted average of the "surpluses" of the three negotiating governments.

Since the governments always have the option to reject the agreement, their surpluses are calculated, in the cases of countries $A$ and $B$, with respect to the FTA and, in the case of country $C$, with respect to status quo. In other words, the "threat points" of the Nash problem will be the joint welfare of government and domestic lobbies before the multilateral liberalization is negotiated.'

Similar to the result obtained in Grossman-Helpman's FTA model, we find that exclusions are granted to industries for which the weighted difference between the political benefits in the exporting countries and the political costs in the importing countries is most negative. I further look for identifying the industry exclusions by performing an ordering that depends only on aggregate conditions and on supply and demand characteristics. Once again, it turns out that the same factors that determine the politically optimal set of exclusions at a unilateral stance also determine the set of exclusions in the multilateral negotiation process.

\section{Multilateral Liberalization from Status Quo}

What are the chances that the three countries liberalize trade multilaterally, provided that none of them is member of an FTA? In this case, governments $A, B$, and $C$ will favor a multilateral agreement without exclusions if and only if,

$$
\sum_{i} \Pi_{i M}^{j}+a W_{M}^{j} \geq \sum_{i} \Pi_{i N}^{j}+a W_{N}^{j}, \text { for } j=A, B, C
$$


i.e., if the political welfare from multilateral liberalization is greater than that from status quo in each country.

Furthermore, the multilateral liberalization with exclusions is described by means of a Nash bargaining problem, where the surpluses of the three governments are calculated with respect to the status quo. ${ }^{10}$

The question, however, is whether the countries have more incentives to liberalize trade departing from the FTA position or from status quo. For this analysis, naturally, it is sufficient to consider the pure cases, i.e., the cases without exclusions to either the FTA or the status quo. This is so because, for each case, we must compare the changes in the political welfare toward global liberalization. If we, for example, consider exclusions at the stage of negotiations for the FTA, then the changes in political welfare from the FTA position will be such that those corresponding to the excluded industries will cancel out with the changes in political welfare from the status quo position. If we, for example, consider exclusions at the stage of negotiations for the multilateral liberalization, then we will find the following scenario. Suppose that, without exclusions permitted, the prospects of multilateral liberalization are higher from the status quo position than from the FTA position. Then, for a particular set of exclusions at the FTA that help favor the multilateral agreement (the most sensitive ones), we would also find another set of sectors excluded at the status quo level that help favor the global agreement (also the most sensitive ones), and will enhance the prospects to reach the accord. The reverse case also holds.

Following the preceding reasoning, and operating on (12), (13) and (16), one obtains the natural answer that the sole presence of a political-welfare improving FTA will lower the prospects for multilateral liberalization with respect to the status quo [inequality (9) must hold for both $A$ and $B$ ].

In the next section, I will show that under certain conditions an FTA is viable (with and without exceptions), yet, the multilateral liberalization is not feasible under any circumstance.

\section{$\overline{\text { An Illustration }}$}

In order to narrow the set of general results found in the preceding section, I will work here with a particular specification of the model introduced originally in Grossman and Helpman (1993). I will depart from that setting to study both the determinants of FTAs and the determinants of multilateral liberalization. 
Suppose that households in the three countries share identical utility functions, where all the non-numeraire goods enter symmetrically and each $u_{i}($.$) is qua-$ dratic. Then, the aggregate demand for any good $i$ in country $j$ has the linear form

$$
D_{i}^{j}\left(q_{i}^{j}\right)=D-b q_{i}^{j},
$$

for $i=1, \ldots, n$ and $j=A, B, C$, where $D$ and $b$ are both positive parameters.

Assume that the supply of each good is symmetrically inelastic in both countries $A$ and $B$. The first country has supply $X_{i}^{A}=\theta X$ in $s \times n$ industries, and $X_{i}^{A}=(1-\theta) X$ in $(1-s) \times n$ industries. The second country has supply $X_{i}^{B}=(1-\theta) X$ in $s \times n$ industries, and $X_{i}^{B}=\theta X$ in $(1-s) \times n$ industries. The parameter $s$ indicates the fraction of a type of industries in each country, whereas the parameter measures output imbalance in any one sector, i.e., the relative size of output in any sector in each country. Without loss of generality, consider $\theta>1 / 2$ and $s \geq 1 / 2$. Assume that country $C$ is an exporter of all goods, and that it can supply any quantity at given world prices standardized at 1 . This assumption is introduced in the illustration in order to avoid terms of trade effects created by externalities that may emerge from the formation of any agreement.

The illustration consists of two stages. In the first stage, I will analyze the economic effects of an FTA between $A$ and $B$. As one expects, this does not affect country $C$ 's welfare since the international price is unchanged. Later, I will focus on the viability of multilateral liberalization between $A, B$, and $C$. It is clear that, once again, this will not affect outcomes in $C$, thus this country will be indifferent toward the agreement. Further, I will study the scenario where countries $A, B$, and $C$ evaluate their prospects for multilateral agreement, starting from status quo. Finally, I will contemplate the cases in which sets of industries are allowed to be excluded from the agreements.

The viability of any agreement, whether bilateral or multilateral, depends on the initial structure of MFN tariffs. In this sense, assume that tariffs initially protecting the import-competing industries in each economy result from a lobbying game as derived in Grossman and Helpman (1994). Further, suppose that politicians in each country place the same weight $a$ on aggregate welfare. Thus, given the set of assumptions made so far, we obtain the following domestic prices in $A$ and $B$ :

$$
\tau_{i}^{j}=1+\frac{x_{i}^{j}}{a b^{\prime}}
$$


for $j=A, B$, and for all sectors in which imports are positive in the initial equilibrium. Regarding country $C$, remember that being the exporter of all goods implies that $\tau_{i}^{C}=1$ for all $i$.

Grossman and Helpman (1995) emphasize that different types of outcomes may emerge in this example depending on the parameter values. According to this idea, we can examine three different sets of parameter restrictions illustrating some relevant cases that may appear.

I will focus on one of those sets of parameters in order to study the case in which an FTA certainly emerges in the first step. This is the case in which all sectors experience enhanced protection. For the remaining sets of parameters, all sectors experience reduced protection, and an FTA will not be feasible, even with exceptions. Moreover, it is clear that a multilateral liberalization will not be feasible either, as they would also imply reduced protection for all industries, in both countries $A$ and $B$.

\section{Viability of an FTA}

Suppose that $A$ and $B$ start negotiating on an FTA. Consider the following restriction on the parameters"

$$
X<D-b\left(1+\frac{\theta X}{a b}\right) \text {. }
$$

Under this condition, all $n$ goods are imported in both countries in the initial equilibrium. Country $A$ has the higher import tariff in the fraction $s$ of industries where its supply is $\theta X$, while country $B$ has the higher import tariff in the remaining sectors. Under an FTA, each country will import from its partner all goods on which their MFN tariffs are higher. Then, $A$ would import from $B$ a fraction $s$ of goods, while $B$ would import from $A$ the remaining goods. Also, the restriction above implies that output in the low-tariff country would not suffice to satisfy import demand in the partner country at its pre-FTA domestic price. As a result, all sectors will experience enhanced protection.

One can calculate the contribution of both types of industry to the change in the joint welfare of government and lobbies from the agreement. Given these contributions, one finds that an FTA is supported in country $B$ for every $s \geq 1 / 2$, while country $A$ will favor the agreement if and only if

$$
s \leq \frac{1}{2}+\frac{\theta-1 / 2}{2 \theta-1+2 a \theta}<1 .
$$


Notice that inequality (20) will only be satisfied for $s$ sufficiently close to 1/2.

Consider now the possibility that governments grant exclusions to a number of sensitive industries. The Grossman-Helpman's approach provides, through this illustration, the idea that exceptions can save an otherwise unfeasible FTA. Consider the proposal to exclude a number $E^{A}$ of sectors in which $A$ would import from $B$, and a number $E^{B}$ of sectors in which $B$ would import from $A$, and let $E^{A}+E^{B} \leq E$ be the WTO rule.

Recalculating the joint welfare change of government and lobbies in country $A$ under the possibility of exclusions, we obtain the following range of values of $\mathrm{s}$ for which an FTA would be feasible:

$$
s \leq \frac{1}{2}+\frac{\theta-1 / 2}{2 \theta-1+2 a \theta}+\frac{a \theta E^{A}-(2 \theta-1+a \theta) E^{B}}{n(2 \theta-1+2 a \theta)} .
$$

It can be shown that if $E^{A}>(2 \theta-1+a \theta) E^{B} / a \theta$, then inequality (21) implies an expansion of the range of $s$ for which the agreement is accepted by $A$. At the same time, if $E^{A}<\left[E^{B} a \theta+(2 s-1) n a \theta+\operatorname{sn}(2 \theta-1)\right] /(2 \theta-1+a \theta)$, then the FTA with exclusions is also supported by government $B$. This is roughly illustrating the fact that there are values of $s$ for which the FTA would be rejected without sectors exclusions, but favored with them. In particular, one can show that if $(2 s-1)<E / n$, then the FTA with $E^{A}=(2 s-1) n$ and $E^{B}=0$ satisfies WTO rules and politically dominates the status quo. However, this is not the only set of exclusions that allow for an equilibrium agreement.

So far, we have revisited a particular specification of the model analyzed in Grossman and Helpman (1993). Through this illustration, it is shown that there are cases in which an FTA would fail if all trade has to be included, while it might be preferred if exclusions are allowed. It remains to show that both governments engage indeed in an efficient negotiation process. However, one can be safe from this particular issue, because there are in fact different alternatives assuring that a certain negotiation process would eventually lead to an equilibrium set of exclusions and, consequently, to the acceptance of the agreement in both countries. ${ }^{12}$

\section{The Viability of a Multilateral Agreement}

Now, I will study the viability of a multilateral agreement among countries $A, B$, and $C$. First, I consider the prospects for multilateral liberalization, taking as given that an FTA between $A$ and $B$ has been formed already. For this purpose, I will continue with the assumption that bilateral agreement arises from (and creates) enhanced protection. I will begin by studying the viability of an agreement on all 
trade and, later on, I will analyze the case where a set of industries can be excluded from the agreement. Second, I consider the prospects for multilateral liberalization, starting from status quo, i.e., assuming that the three countries engage in only one round of multilateral negotiation.

In the first case, notice that all industries in country $A$ and $B$ will experience reduced protection after the multilateral agreement, since all goods are exported by the low-price country $C$. As a result of the multilateral liberalization on all trade, the contributions of the two types of sectors to the change in the joint welfare of both countries are negative, for any previously configured set of sectors excluded from the FTA. This gives us the first result from this illustration. ${ }^{13}$

Result 1: The multilateral trade agreement without exceptions is not favored either in $A$ or $B$, for any set of exceptions that may have arisen in the equilibrium FTA.

Consider now the possibility of allowing for exclusions to the multilateral liberalization. In this case, the WTO rule would admit $E^{A}+E^{B}+E^{C} \leq E$. However, country $C$ will be indifferent about the agreement as it is the exporter country. Thus, one can further set $E^{C}=0$.

According to the previous discussion, now assume that the first-step negotiation on the FTA provided the least set of exclusions: $E^{A}=(2 s-1) n$ and $E^{B}=0$. One expects that the industries excluded from the original FTA continue to be excluded from the multilateral liberalization, given their relative high cost to the welfare of both $A$ and $B$. Denote as $E_{M}^{A} \subset E^{A}$ the set of exclusions to the multilateral agreement, out of the set of exclusions from the FTA stage. Setting the least set of exclusions possible, $E_{M}^{A}=(2 s-1) n$, we find that there is no $E^{A}$ and $E^{B}$ such that the joint welfare changes in both countries $A$ and $B$ are positive at the same time. This leads to the second result from this illustration.

Result 2: The multilateral trade agreement with industry exclusions is not favored either in $A$ or $B$, for any set of exceptions that may have arisen in the equilibrium FTA.

This result comes from the fact that any increase in the set of exclusions that may favor the agreement in $A$ leads to a rejection by country $B$, and vice versa. Roughly, this occurs because both countries experience reduced protection in all industries from the multilateral liberalization. 
Now the question is, was the multilateral liberalization feasible before countries $A$ and $B$ have engaged in an agreement? In other words, did the FTA between these two countries impede the multilateral agreement? In what follows, 1 will analyze the viability of a multilateral agreement starting from status quo.

We will arrive at the conclusion that, beginning from a position where no country has a trade agreement, the status quo is preferred to the multilateral liberalization in both countries, while country $C$ is still indifferent. Furthermore, the rejection of the agreement arises because countries $A$ and $B$ experience reduced protection in all their industries. In this sense, even though aggregate welfare increases in both countries as a result of a fall in prices, the decrease in profits from the importcompeting industries is high enough to make the political welfare changes negative. If one allows for exclusions to the grand accord, rejection results do not change. This leads to the third result from this illustration.

Result 3: The multilateral trade agreement, either with industry exclusions or without them, is not feasible from the status quo position.

Given results 1 and 2, the third result completes the set of (political) conditions supporting the view of FTAs as being partial building blocs, i.e., these agreements can be feasible when the multilateral agreement is not.

To summarize, I have revisited a particular specification first appeared in Grossman and Helpman (1993), where an FTA between two countries ( $A$ and $B$ ) is feasible under certain conditions. They show that the prospects for a bilateral agreement increase when one allows for a number of exclusions in the sensitive import-competing sectors. Afterwards, I have analyzed the viability of a multilateral agreement by introducing a third country $(C)$. Based on the assumptions made above, it is not required that country $C$ be active in the negotiations process because it is indifferent about any agreement. In spite of this simplicity, this setting allows us to think about the possibilities that arise for country $A$ and $B$ to coordinate a reduction of tariffs.

We have observed that the political conditions do not help in providing a good reception toward the agreement in either $A$ or $B$ (with exclusions and without them). The reason is the presence of a reduced-protection effect in all sectors in both economies. However, global free trade was not feasible from status quo either. As such, one can assert that, for a special characterization of the Grossman-Helpman framework, FTAs become partial building blocs. 


\section{Concluding Remarks}

The big picture issue of this paper is related to the dynamic path of trading blocs and whether preferential trade agreements are building or stumbling blocs.

To address this issue, I have initially departed from Grossman and Helpman's (1995) model of FTAs. That model was designed to explain the viability of a free trade agreement between two small countries where governments not only maximize aggregate welfare but also take into account the contributions from domestic special-interest groups. The model also provides the conditions needed for the agreements to be politically viable with some exceptions on sensitive industries.

I have taken that approach to explain a bilateral formation and have extended it to study the viability of a grand accord with a third potential partner. The extension is intended to investigate the conditions for multilateral liberalization to be politically viable both from a position where an FTA already exists and from status quo.

We have observed that an extension to the model's general form does not help us to determine whether an FTA is a building or a stumbling bloc. However, we do find that, provided an FTA exists, the chances for favoring a multilateral agreement will fall. One might guess that finding a global agreement with exclusions is less likely than finding an FTA with exclusions. This stems from the fact that the set of outcomes in which an agreement is favored on a multilateral bargaining must shrink. This conjecture is not proved here, and is left for future research. However, an illustration with specific functional forms helps us characterize the viability of a multilateral liberalization.

For a set of restrictions on the parameters, reduced protection arises on all industries if the FTA is formed. In these cases, results are not appealing since a bilateral agreement does not emerge in the first stage and neither multilateral agreement is feasible from status quo. This happens because of the assumptions made on the two negotiating countries, and in particular, because reduced protection leads industries to successfully pressurize the government in favor of status quo.

For another set of restrictions, enhanced protection arises from the FTA. In these cases, alternatives exist in which an FTA is feasible and, furthermore, these alternatives expand when exclusions are permitted. Nevertheless, I have shown that, at a second-stage, a multilateral liberalization is not viable under any circumstance: with exclusions or without them. The multilateral liberalization is also not feasible from status quo.

To sum up, there exists a set of conditions under which an FTA acts, in a limited sense, as a partial building bloc: when the global accord is not feasible under 
any scenario, a political-welfare improving FTA can be attainable. A bilateral agreement does not raise aggregate welfare for it generates enhanced protection. Neither it serves for the signing countries to get closer from multilateral liberalization. Yet, the results imply that, under certain conditions, this is the situation to which countries would eventually converge. That is, there will be a scenario with a large number of FTAs, where governments and lobbies maximize their joint welfare. In order to have a more robust answer regarding the viability of a multilateral trade agreement, we must relax the strong assumptions made in the illustration. Nonetheless, I believe this work constitutes a step forward in our understanding of the dynamic-path issue of trading blocs from a political-economy perspective.

\section{Notes}

1. This is a shortened version of a paper written under a grant from the Private Enterprise Research Center at Texas A\&M University. I am grateful to Kishore Gawande for numerous conversations on this topic. I also thank Amy Glass, Kamal Saggi, the Editor, an anonymous referee, and seminar participants at Texas A\&M University and Sam Houston State University for helpful comments. All errors are my own.

2. In what follows, I will use indistinctly the terms FTA and PTA. The latter is more general in the sense that it implies a reduction of external tariffs among members (including, of course, the possibility of lowering tariffs to zero), whereas the former implies the simple elimination of members' tariffs. Since this work will treat any agreement as simply removing barriers, then both agreements are identical. Note that, in addition, one may consider other types of trade agreements such as a customs union (an agreement whereby all members impose a common external tariff), yet, I restrict the analysis here to the FTA case.

3. See Panagariya (2000) for a survey of this literature.

4. In practice, the size of the set of exceptions should not violate the WTO clause which states that an FTA should cover isubstantially all trade".

5. Grossman and Helpman (1995, pp. 669) recognize the importance of relaxing this assumption. In a paper related to this literature, a different approach taken by Ornelas (2005) allows for external tariffs to be endogenous after a trade agreement. He shows that strategic and distributive effects of an FTA reduce the importance of politics in defining a multilateral trade liberalization. An extension on this line, however, is beyond the scope of this paper. 
6. This restriction, which in a sense is obeying WTO rules, can be more general. For instance, another restriction could be expressed as a limit on the fraction of excluded trade.

7. The reader may find the details of the formal problem in Grossman and Helpman (1995).

8. Assume, for simplification, that the number of restrictions $T$ is the same as the one for the FTA.

9. The formal problem is described in a Technical Appendix, which can be obtained from the author upon request.

10. The formal problem is described in the Technical Appendix.

11. See Grossman and Helpman (1993) for the details regarding the origin of these restrictions.

12. Grossman and Helpman (1993) suggest that this bargaining process can be modeled as an alternating bargaining game a la Binmore et al. (1986). On the other hand, as I mentioned above, Grossman and Helpman (1995) solve this bargaining problem by applying a Nash solution.

13. The detailed proofs of these results can be obtained from the author.

\section{References}

Aghion, P., P. Antràs, \& Helpman, E. (2007). Negotiating free trade. Journal of International Economics, 73(1), 1-30.

Bhagwati J. (1991). The world trading system at risk. Princeton, NJ: Princeton University Press.

Bhagwati, J. (1993). Regionalism and multilateralism: An overview. In J. de Melo \& A. Panagariya (Eds.), New dimensions in regional integration. Cambridge: Cambridge University Press.

Bhagwati J. (1995). US trade policy: The infatuation with free-trade areas. In J. Bhawati \& A. Kruger (Eds.) The dangerous drift to preferential trade agreements. Washington, DC: American Enterprise Institute for Public Policy Research.

Binmore, K., Rubinstein, A., \& Wolinsky, A. (1986). The Nash bargaining solution in economic modeling. Rand Journal of Economics, 17, 176-188.

Gawande, K., Sanguinetti, P., \& Bohara, A. (2005). Exclusions for sale: Evidence on the Grossman-Helpman model of free trade agreements, Mimeo. 
Goldberg, P., \& Maggi, G. (1999). Protection for sale: An empirical investigation. American Economic Review, 89, 1135-1155.

Grossman, G., \& Helpman, E. (1993). The politics of free-trade agreements, NBER Working Paper No. W4597.

Grossman, G., \& Helpman, E. (1994). Protection for sale. American Economic Review, 84, 833-850.

Grossman, G., \& Helpman, E. (1995). The politics of free-trade agreements. American Economic Review, 85, 667-690.

Krishna, P. (1998). Regionalism and multilateralism: A political economy approach. The Quarterly Journal of Economics, 113, 227-252.

Krishna, V., Serrano, R. (1996). Multilateral bargaining. Review of Economic Studies, 63, 61-80.

Ornelas, E. (2005). Rent destruction and the political viability of free trade agreements. Quarterly Journal of Economics, 120(4), 1475-1506.

Panagariya, A. (2000). Preferential trade liberalization: The traditional theory and new developments. Journal of Economic Literature, 38, 287-331.

Saggi, K., \& Yildiz, H. M. (2006). Bilateral trade agreements and the feasibility of multilateral free trade, Mimeo.

Summers, L. (1991). Regionalism and the world trading system. Policy implications of trade and currency zones. Federal Reserve Bank of Kansas City, 295-301.

Viner, J. (1950). The customs union issue. New York: Carnegie Endowment for 1nternational Peace.

\section{Biographical Sketch of Author}

Danilo R. Trupkin is a Professor of Economics at the Universidad de Montevideo, Uruguay. His research interests are in the areas of macroeconomics, monetary economics, and international trade. He is the Editor of Revista de Ciencias Empresariales y Economia. Dr. Trupkin has collaborated as a researcher in a number of projects on international trade policy at Torcuato Di Tella University and the UnderSecretariat of Foreign Trade at the Ministry of Economy of Argentina. He earned his Ph. D. in Economics from Texas A\&M University, College Station (TX). 